Supporting information

\title{
Microfluidic Fabrication of Structure-controlled Chitosan microcapsules via Interfacial Crosslinking of droplet templates
}

Xiao-Ting Mu, , Yao Li, , Xiao-Jie Ju, ${ }^{*},+,+$ Xiu-Lan Yang, ${ }^{\dagger}$ Rui Xie, ${ }^{\dagger,+}$ Wei Wang, ${ }^{\dagger,+}$ Zhuang Liu, ${ }^{\dagger,+}$ and Liang-Yin Chut,

${ }^{\dagger}$ School of Chemical Engineering, State Key Laboratory of Hydraulics and Mountain River Engineering, Sichuan University, Chengdu, Sichuan 610065, P. R. China

\$State Key Laboratory of Polymer Materials Engineering, Sichuan University, Chengdu, Sichuan 610065, P. R. China

*Corresponding Author. E-mail: juxiaojie@,scu.edu.cn 


\section{Figures}

(a)

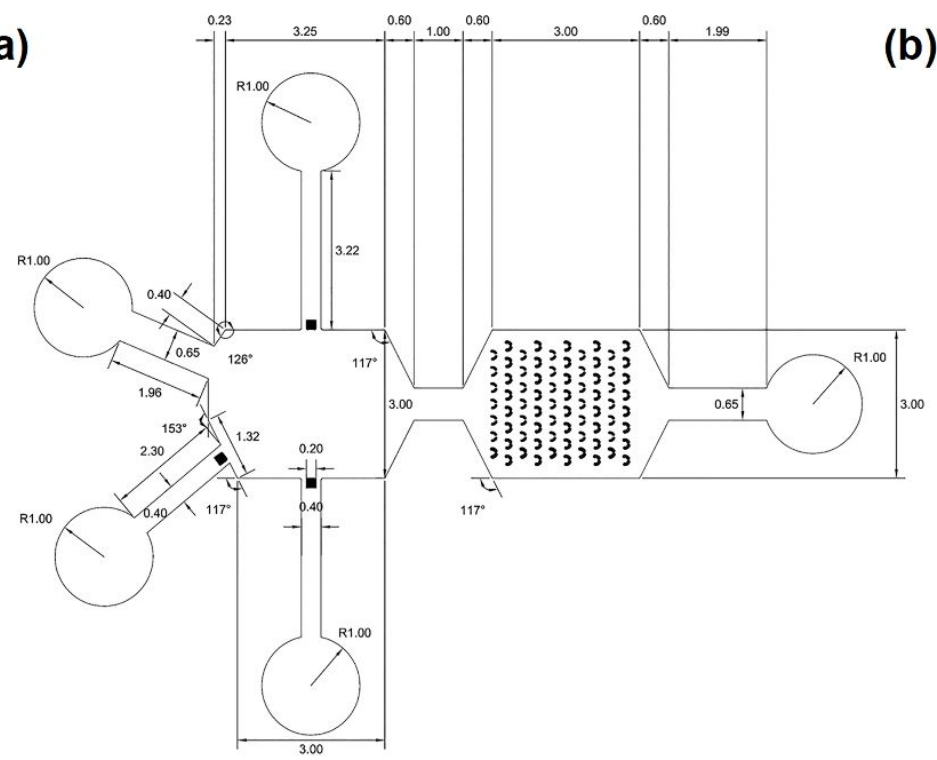

(b)

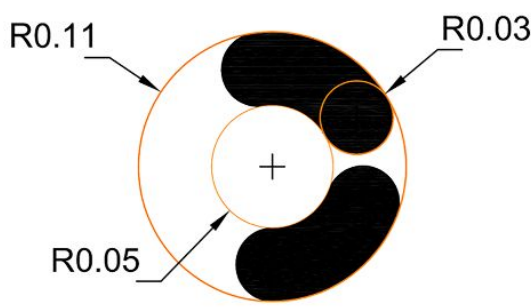

Figure S1. The design illustration of the PDMS droplet capture chip. (a) The plan drawing of the PDMS droplet capture chip with dimensioning. (b) The dimensioning of the droplet capture trap arrayed in the PDMS droplet-capture chip. Unit: mm. 


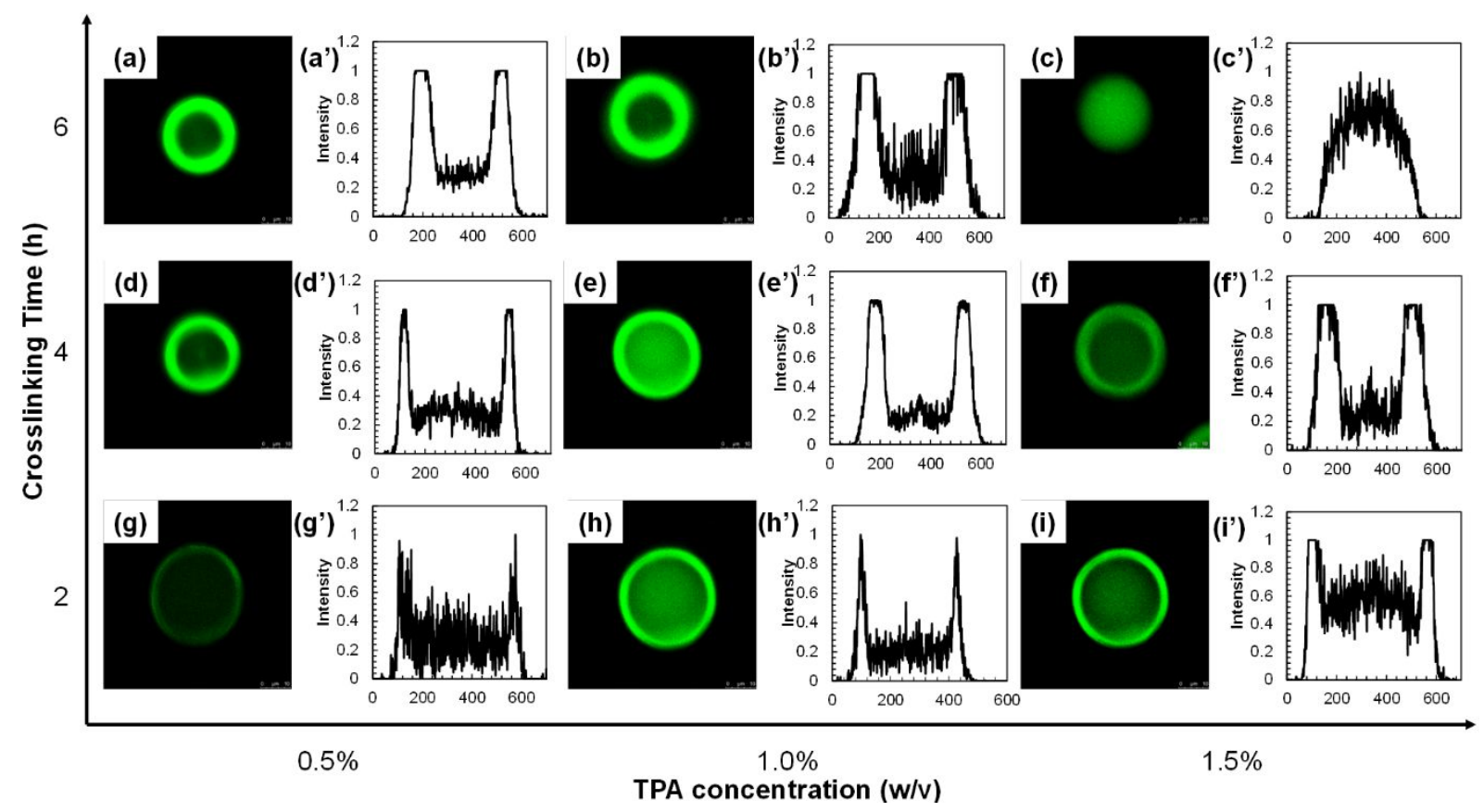

Figure S2. CLSM images and fluorescence intensity distribution of chitosan microcapsules with controllable structure crosslinked with TPA concentrations increase from $0.5 \mathrm{wt} \%$ to 1.5 $\mathrm{wt} \%$ and crosslinking time changes from $2 \mathrm{~h}$ to $6 \mathrm{~h}$. 

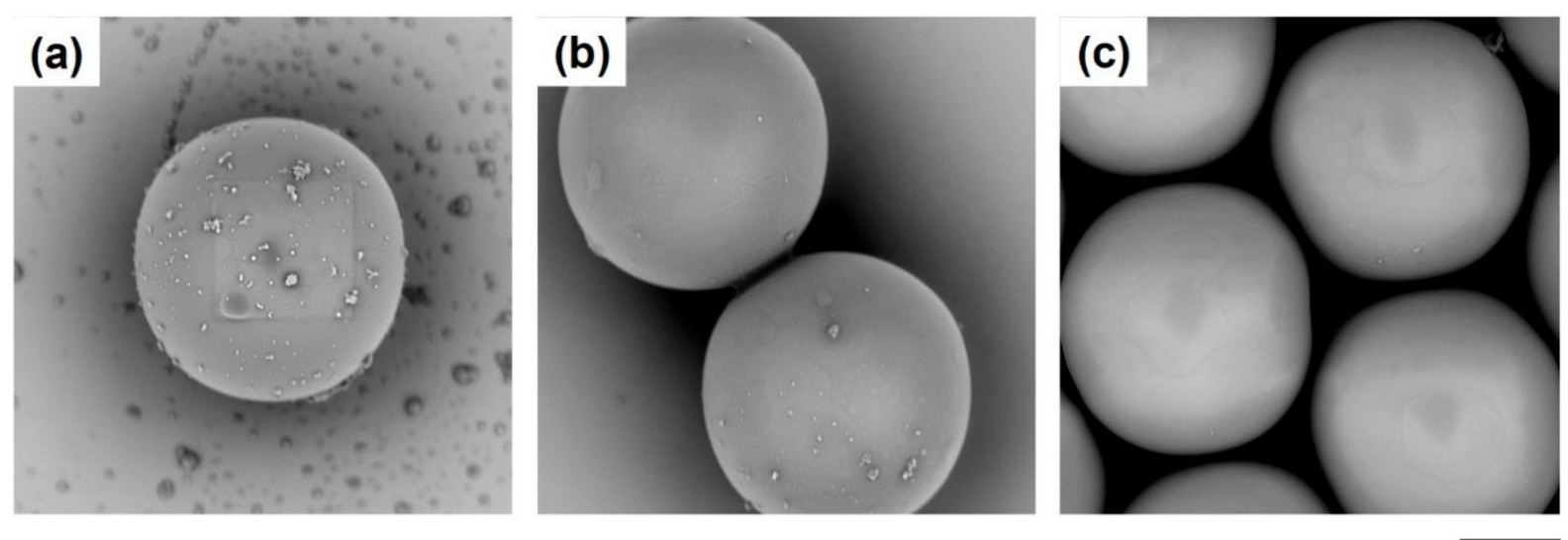

Figure S3. SEM images of chitosan microcapsules crosslinked for (a) 2 h, (b) 4 h, (c) $6 \mathrm{~h}$ with TPA concentration of $1 \mathrm{wt} \%$ and chitosan concentration of $4 \mathrm{wt} \%$ in non-captured condition. Scale bar $10 \mu \mathrm{m}$. 
(a)
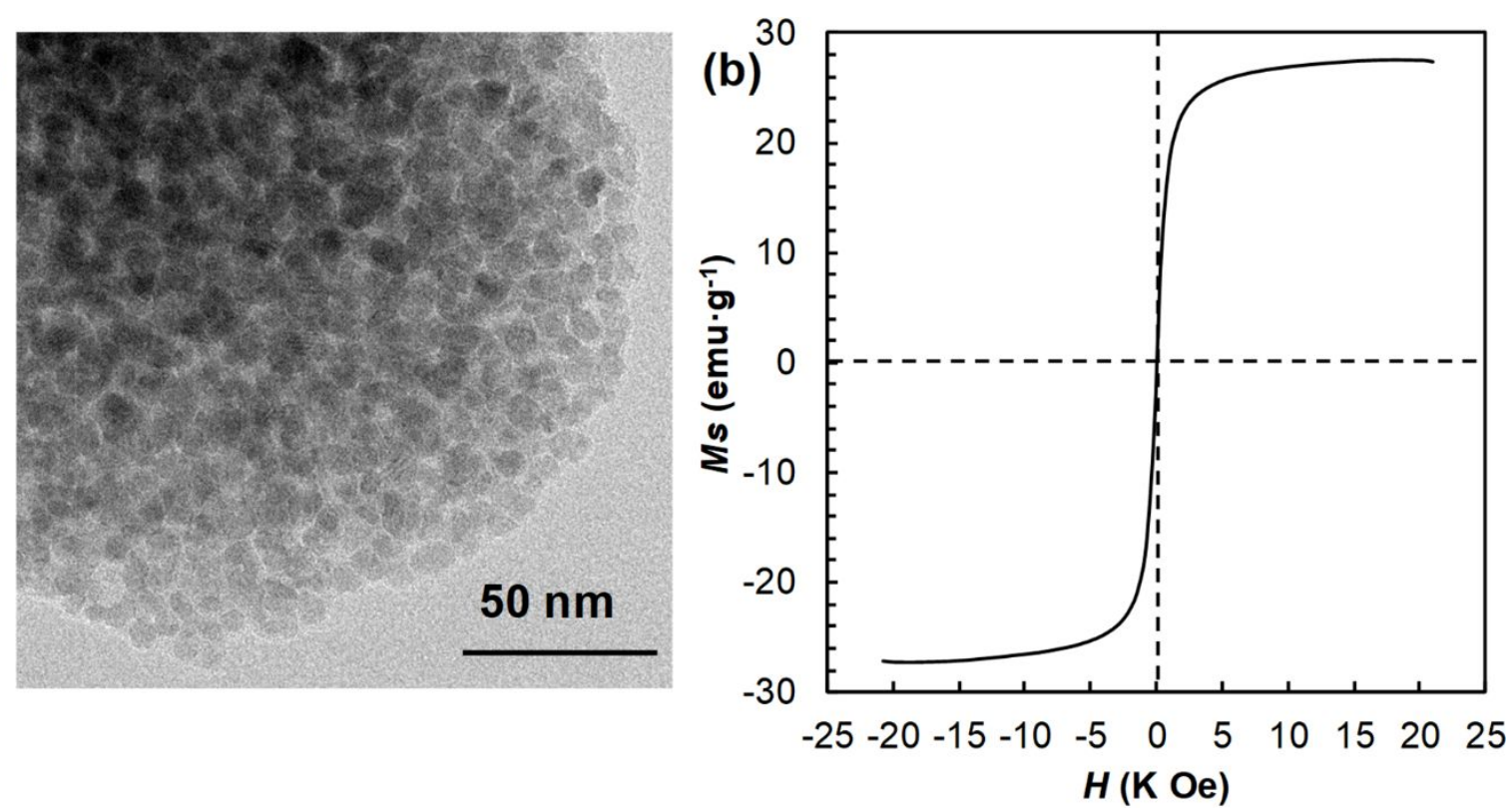

Figure S4. (a) TEM image of $\mathrm{Fe}_{3} \mathrm{O}_{4}$-MNPs. (b) Magnetization hysteresis loop (7400, Lakeshore) of $\mathrm{Fe}_{3} \mathrm{O}_{4}$-MNPs at room temperature. 


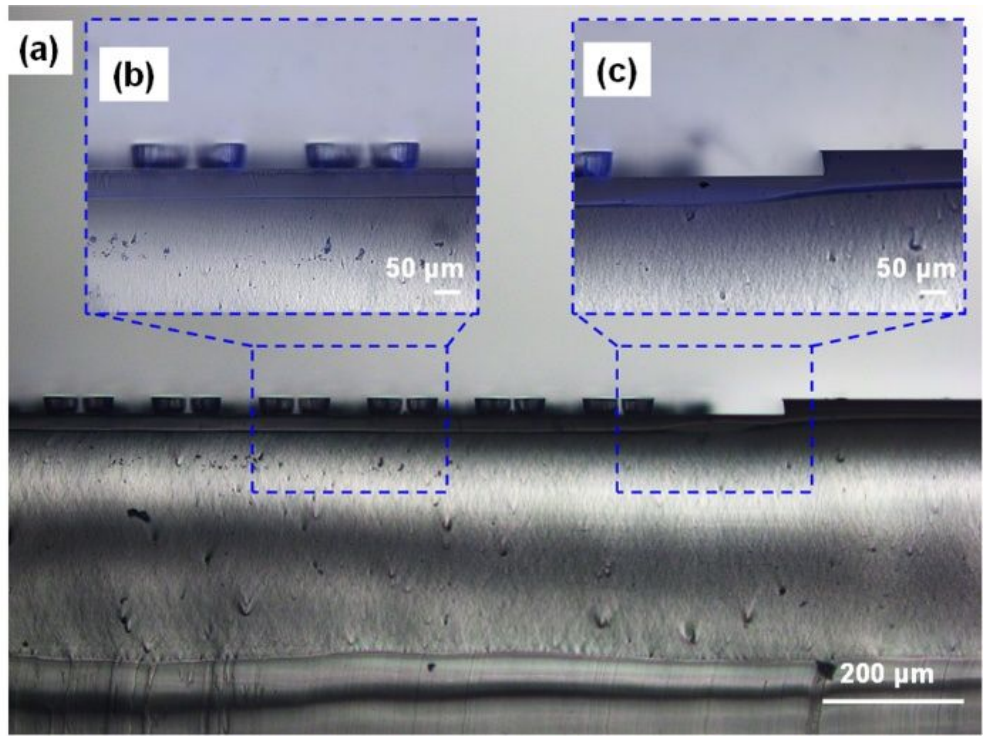

Figure S5. Optical micrographs of the cross-sectional views of microchannels in the PDMS chip: (a) general view, (b) the droplet capture traps, (c) the periphery of the microchannels. 


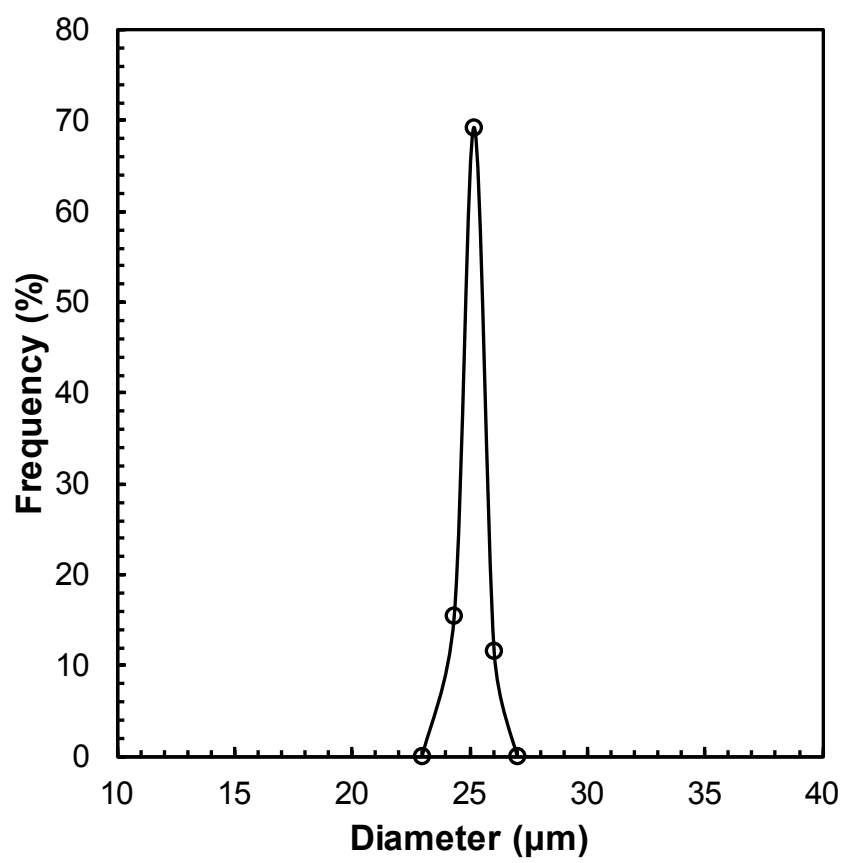

Figure S6. The size distribution of the microcapsules crosslinked by $\mathrm{W} / \mathrm{O}$ emulsion templates with average diameter of $86 \mu \mathrm{m}$ in online experiment. 


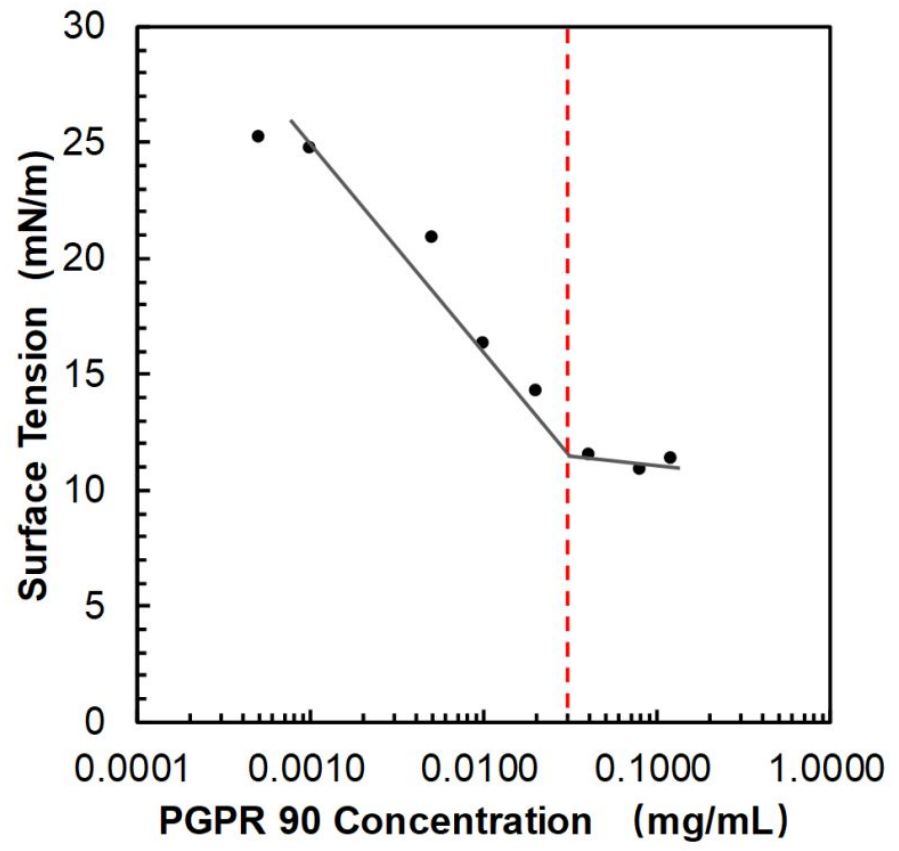

Figure S7. Interfacial tensions of mixture solution of soybean oil and benzyl benzoate / chitosan aqueous solution as a function of PGPR concentration. 
Due to the autofluorescence, chitosan microcapsules exhibit two emission bands when excited at $488 \mathrm{~nm}$, and the strongest emission band is observed in the range of 495 550 nm. And the model drug FITC-dextran shows a strong fluorescent emission band in the range of $520 \sim 530 \mathrm{~nm}$. That is, the emission bands of chitosan microcapsules and FITC-dextran are overlapped partially, making it difficult to observe the distribution of FITC-dextran in chitosan microcapsules from the CLSM images. To specifically characterize the internal structure of the drug-loaded microcapsules, the model drug FITC-dextran in the inner fluid containing $4 \mathrm{wt} \%$ chitosan, $0.5 \mathrm{wt} \%$ HEC is replaced by $0.5 \mathrm{wt} \%$ fluorescent amine-modified polystyrene nanobeads (mean size $100 \mathrm{~nm}, \lambda_{\mathrm{ex}} \sim 475 \mathrm{~nm}, \lambda_{\mathrm{em}} \sim 540 \mathrm{~nm}$, Sigma-Aldrich) to prepare the W/O emulsion templates. The fluorescent nanobeads-loaded chitosan microcapsules with different shell thicknesses are fabricated by controlling the interfacial crosslinking reaction time for $2 \mathrm{~h}$, $4 \mathrm{~h}$ and $6 \mathrm{~h}$ in off-line manner. The CLSM images of these fluorescent nanobeads-loaded chitosan microcapsules with different structures are shown in Figure S8 excited at $488 \mathrm{~nm}$. Figures S8(a1-c1) are the fluorescence images of crosslinked chitosan shell, Figures S8(a2-c2) are the fluorescence images of the loaded fluorescent nanobeads, and Figures S8(a3-c3) are the overlapped images. It can be seen that, as crosslinking time increases, the shell of chitosan microcapsules increases and the inner cavity of the microcapsules decreases, meanwhile, the fluorescent distribution of nanobeads in the microcapsules decreases. That means the drug loading capacity is related to the inner cavity size of chitosan microcapsules, which can be easily controlled by regulating the relative shell thickness of the microcapsules.

Additionally, the degradation of chitosan microcapsules with different structures at $\mathrm{pH} 4$, pH 5 and pH 5.8 is shown in Movie S1. The chitosan microcapsules are prepared by controlling the crosslinking time of $2 \mathrm{~h}, 4 \mathrm{~h}$ and $6 \mathrm{~h}$ with a template diameter of $85 \mu \mathrm{m}$ and TPA of $1.0 \%$. It can be seen that these chitosan microcapsules are easier to degraded under lower $\mathrm{pH}$ conditions; and microcapsules with smaller relative shell thickness have a faster degradation rate. 


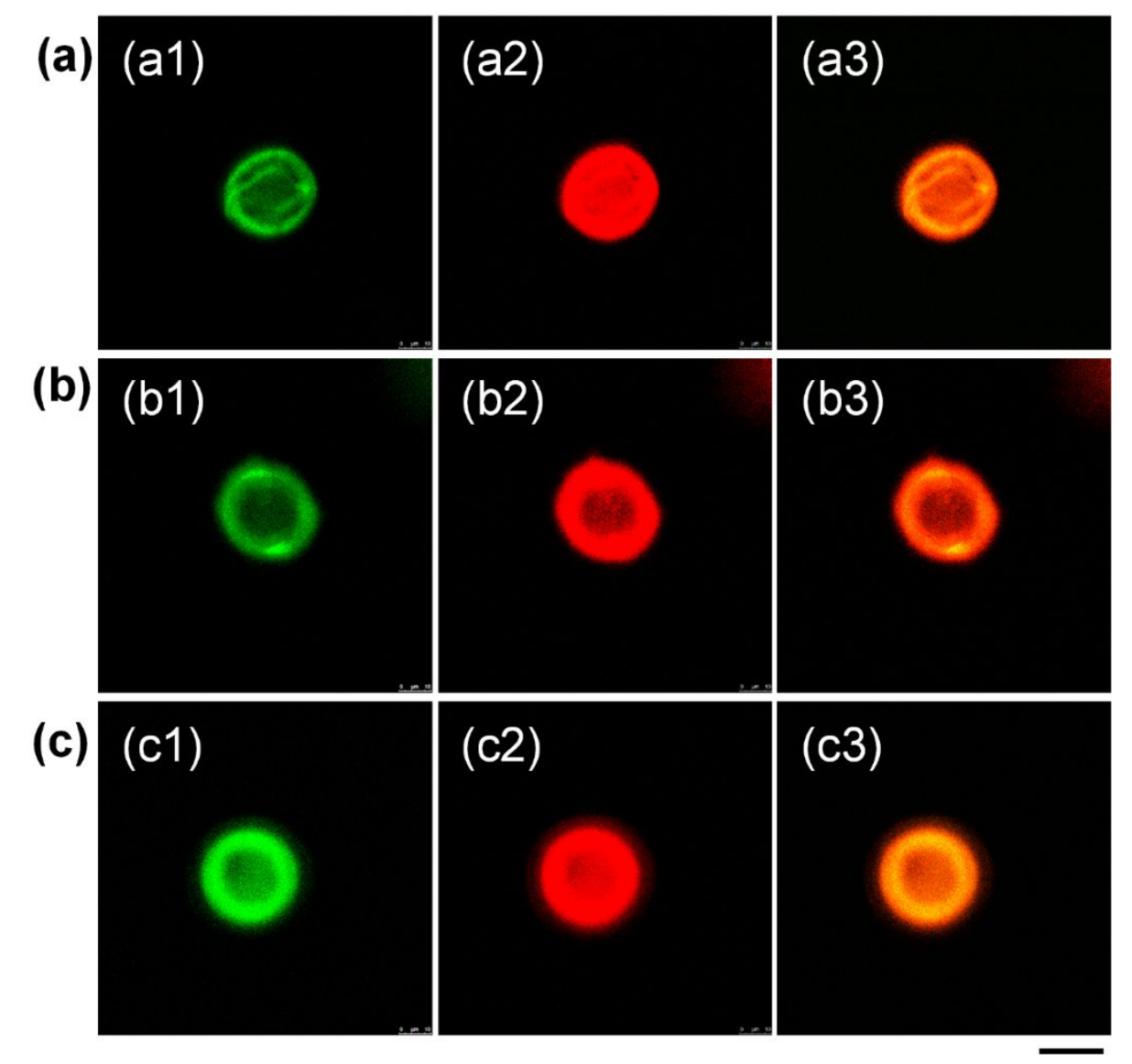

Figure S8. CLSM images of fluorescent nanobeads-loaded chitosan microcapsules crosslinked for $2 \mathrm{~h} \mathrm{(a),} 4 \mathrm{~h} \mathrm{(b)}$ and $6 \mathrm{~h}$ (c) with 1wt\% TPA: (a1-c1) on chitosan fluorescent channel, (a2c2) on fluorescent nanobeads fluorescent channel, and (a3-c3) overlay channels. Scale bar 20 $\mu \mathrm{m}$. 
Movie

Movie S1. Degradation of chitosan microcapsules with different structure at different $\mathrm{pH}$ $\underline{(\mathrm{AVI})}$ 


\section{Tables}

Table S1. The size reduction of crosslinked chitosan W/O emulsion droplets in different preparing conditions.

\begin{tabular}{cccccc}
\hline $\begin{array}{c}\text { Initial } \\
\text { Diameter }\end{array}$ & $\begin{array}{c}\text { TPA } \\
\text { Concentration }\end{array}$ & $\begin{array}{c}\text { PGPR } \\
\text { Concentration }\end{array}$ & Reaction Condition & $\begin{array}{c}\text { Final } \\
\text { Diameter }\end{array}$ & $\begin{array}{c}\text { Final Size } \\
\text { Reduction }\end{array}$ \\
\hline & $1.5 \mathrm{wt} \%$ & $4 \mathrm{wt} \%$ & Batch Operation & $26.1 \mu \mathrm{m}$ & $69.3 \%$ \\
& $0.5 \mathrm{wt} \%$ & $4 \mathrm{wt} \%$ & Batch Operation & $28.0 \mu \mathrm{m}$ & $67.0 \%$ \\
& $1 \mathrm{wt} \%$ & $4 \mathrm{wt} \%$ & Batch Operation & $28.1 \mu \mathrm{m}$ & $66.9 \%$ \\
& $1 \mathrm{wt} \%$ & $12 \mathrm{wt} \%$ & Batch Operation & $26.6 \mu \mathrm{m}$ & $68.7 \%$ \\
& $1 \mathrm{wt} \%$ & $8 \mathrm{wt} \%$ & Batch Operation & $28.4 \mu \mathrm{m}$ & $66.5 \%$ \\
& $1 \mathrm{wt} \%$ & $4 \mathrm{wt} \%$ & Continuous Operation & $24.7 \mu \mathrm{m}$ & $70.9 \%$ \\
& $0.5 \mathrm{wt} \%$ & $4 \mathrm{wt} \%$ & Continuous Operation & $26.8 \mu \mathrm{m}$ & $68.5 \%$ \\
& $1.5 \mathrm{wt} \%$ & $4 \mathrm{wt} \%$ & Continuous Operation & $24.2 \mu \mathrm{m}$ & $71.5 \%$ \\
& $1 \mathrm{wt} \%$ & $8 \mathrm{wt} \%$ & Continuous Operation & $25.5 \mu \mathrm{m}$ & $70.0 \%$ \\
$65 \mu \mathrm{m}$ & $1 \mathrm{wt} \%$ & $12 \mathrm{wt} \%$ & Continuous Operation & $24.0 \mu \mathrm{m}$ & $71.8 \%$ \\
& $1 \mathrm{wt} \%$ & $4 \mathrm{wt} \%$ & Batch Operation & $18.8 \mu \mathrm{m}$ & $71.0 \%$ \\
\hline $130 \mu \mathrm{m}$ & $1 \mathrm{wt} \%$ & $4 \mathrm{wt} \%$ & Continuous Operation & $16.9 \mu \mathrm{m}$ & $77.2 \%$ \\
\hline
\end{tabular}


Table S2. Diameters of the chitosan microcapsules/microspheres prepared in different conditions.

\begin{tabular}{cccc}
\hline \multirow{2}{*}{ Crosslinking time (h) } & \multicolumn{3}{c}{ TPA concentration } \\
\cline { 2 - 4 } & $0.5 \mathrm{wt} \%$ & $1.0 \mathrm{wt} \%$ & $1.5 \mathrm{wt} \%$ \\
\hline 6 & $26.0 \mu \mathrm{m}$ & $25.5 \mu \mathrm{m}$ & $24.0 \mu \mathrm{m}$ \\
5 & $27.5 \mu \mathrm{m}$ & $26.8 \mu \mathrm{m}$ & $25.7 \mu \mathrm{m}$ \\
4 & $28.3 \mu \mathrm{m}$ & $27.3 \mu \mathrm{m}$ & $26.1 \mu \mathrm{m}$ \\
3 & $28.3 \mu \mathrm{m}$ & $28.3 \mu \mathrm{m}$ & $26.3 \mu \mathrm{m}$ \\
\hline
\end{tabular}


Table S3. The results of fitting FITC-dextran release profiles by the first-order kinetic model

\begin{tabular}{cccc}
\hline & \multicolumn{3}{c}{$\begin{array}{c}\text { First-order kinetic model } \\
\ln (100-Q t)=K \mathrm{t}+C\end{array}$} \\
\cline { 2 - 4 } Crosslinking Time & $C$ & $K$ & $R^{2}$ \\
\hline $6 \mathrm{~h}$ & 4.5153 & -0.03427 & 0.980104 \\
$4 \mathrm{~h}$ & 4.5633 & -0.03707 & 0.99048 \\
$2 \mathrm{~h}$ & 4.5433 & -0.04492 & 0.99223 \\
\hline
\end{tabular}

$Q_{t}$ : The cumulative release rate of FITC-dextran loaded microcapsules at time $t$.

$C, K, R^{2}$ : Correlation coefficients of the corresponding kinetic models. 
In this work, magnetic-responsive chitosan microcapsules are prepared by crosslinking for $2 \mathrm{~h}, 4 \mathrm{~h}$ and $6 \mathrm{~h}$ with $1 \mathrm{wt} \%$ TPA and $4 \mathrm{wt} \%$ chitosan in non-captured condition, the leaching of $\mathrm{Fe}_{3} \mathrm{O}_{4}$-MNPs from chitosan microcapsules with different structures is investigated by dispersed microcapsules in deionized water $\left(25^{\circ} \mathrm{C}\right)$. After soaking for different time, the $\mathrm{Fe}$ contents in leaching solutions are measured by ICP-AES (VGPQExcell, TJA). The relative leaching ratios of $\mathrm{Fe}_{3} \mathrm{O}_{4}$-MNPs from chitosan microcapsules are calculated and the results are listed in Table S4. It can be seen that after the microcapsules are soaking in water for $100 \mathrm{~h}$, only very trace amounts of Fe (less than $0.017 \mathrm{mg} \cdot \mathrm{L}^{-1}$ ) are detected in the leaching solution. That means the magnetic $\mathrm{Fe}_{3} \mathrm{O}_{4}-\mathrm{MNPs}$ in chitosan microcapsules are embedded relatively stalely. Such trace leaching of $\mathrm{Fe}_{3} \mathrm{O}_{4}$-MNPs may come from the outermost surface of microcapsules. However, when the magnetic-responsive chitosan microcapsules are used for targeted delivery, the time for the microcapsules reach to the destination needs to be considered.

Table S4. The relative leaching ratios of $\mathrm{Fe}_{3} \mathrm{O}_{4}-\mathrm{MNPs}$ from chitosan microcapsules crosslinking for $2 \mathrm{~h}, 4 \mathrm{~h}$ and $6 \mathrm{~h}$.

\begin{tabular}{cccccc}
\hline \multirow{2}{*}{ Sample } & \multicolumn{5}{c}{ Time (h) } \\
\cline { 2 - 6 } & 6 & 12 & 36 & 60 & 100 \\
\hline Microcapsules crosslinking for 6 & $1.5 \%$ & $1.5 \%$ & $1.6 \%$ & $1.7 \%$ & $1.8 \%$ \\
Microcapsules crosslinking for 4 $\mathrm{h}$ & $1.2 \%$ & $1.5 \%$ & $1.5 \%$ & $1.5 \%$ & $1.6 \%$ \\
Microcapsules crosslinking for 2 $\mathrm{h}$ & $1.1 \%$ & $1.39 \%$ & $1.3 \%$ & $1.3 \%$ & $1.3 \%$ \\
\hline
\end{tabular}

